Case Report

\title{
Goiter and Sensorineural Hearing Loss: Pendred Syndrome Should Be Suspected: A Case Report
}

\section{Sana Mallouk*, Zouhair Najib, Omar Iziki, Youssef Oukessou, Sami Rouadi, Reda Abada, Mohamed Mahtar, Mohamed Roubal}

Department of Otorhinolaryngology, Head and Neck Surgery, King Hassan II University Hospital, Casablanca, Morocco

\author{
Email address: \\ sanaa.mallouk@gmail.com (S. Mallouk),najibdoc@gmail.com (Z. Najib), iziki.omar@gmail.com (O. Iziki), \\ oukessou22@gmail.com (Y. Oukessou),samirouadi@gmail.com (S. Rouadi), redaalahabada@gmail.com (R. Abada), \\ mahtar.mohamed1@gmail.com (M. Mahtar),med.roubal@gmail.com (M. Roubal) \\ *Corresponding author
}

\section{To cite this article:}

Sana Mallouk, Zouhair Najib, Omar Iziki, Youssef Oukessou, Sami Rouadi, Reda Abada, Mohamed Mahtar, Mohamed Roubal. Goiter and Sensorineural Hearing Loss: Pendred Syndrome Should Be Suspected: A Case Report. International Journal of Otorhinolaryngology. Vol. 6, No. 2, 2020, pp. 23-25. doi: 10.11648/j.ijo.20200602.11

Received: March 20, 2020; Accepted: May 7, 2020; Published: July 13, 2020

\begin{abstract}
BACKGROUND: Pendred syndrome (PS) is an autosomal recessive disorder, caused by biallelic mutations in the SLC26A4 gene which codes for the pendrin protein. It is characterized by sensorineural hearing loss associated with dyshormonogenic goiter. Which is a common cause of congenital deafness. CASE PRESENTATION: Hereby we describe a case of a 21-year-old women who presented to the ORL department with an anterior cervical mass that gradually increased in volume over 3 years associated with severe hearing loss since birth for which the patient was provided with hearing aids. Pendred syndrome is suspected because of the present of goiter and congenital hearing loss. CONCLUSIONS: Clinical presentation is very variable. However, the association of goiter and progressive deafness suggests the diagnosis of Pendred syndrome.
\end{abstract}

Keywords: Goiter, Sensorineural Deafness, Pendred Syndrome

\section{Introduction}

Pendred syndrome is described for the first time by Vaughan Pendred in 1896; it's an autosomal recessive disorder, characterized by sensorineural hearing loss associated with dyshormonogenic goiter [1]. It is caused by mutations in the Pendred Syndrome (PDS) gene (SLC26A4), encoding Pendrin (multifunctional anion transporter): a protein expressed in the inner, thyroid and kidney [2]. It is a common cause of congenital deafness with a percentage of $10 \%$ [3]. Thus, it is the most common cause of syndromic deafness and the risk of transmission from heterozygous parents is $25 \%$ [4].

We report a case of a 21-year-old patient who presented to the ORL department for goiter, in whom the diagnosis of Pendred syndrome is suspected because of the present of goiter and congenital hearing loss.

We describe this case to raise awareness of this pathology and for better therapeutic management.

\section{Case Repport}

A 21-year-old woman presented to the ENT department for an anterior cervical mass that gradually increased in volume over 3 years. She had a severe hearing loss since birth for which the patient was provided with hearing aids. There was no history elicited of goiter or deafness in the family. On examination she had a large anterior cervical swelling, firm, mobile when swallowing, measuring $2 \mathrm{~cm}$, inferior border was palpable and without palpable lymph nodes. On the nasofibroscopy the two vocal cords are mobile. The rest of systemic examination was normal. Thyroid function tests (TSH, T3 and T4) were normal. Ultrasound scan showed a large multi-hetero-nodular goiter, the largest was in the right lobe, measuring $23 \times 15 \mathrm{~mm}$. The latest audiometry revealed severe bilateral sensorineural hearing loss. CT scan and MRI of Inner Ear showed bilateral vestibular enlargement and 
modiolus deficiency (figure 1).
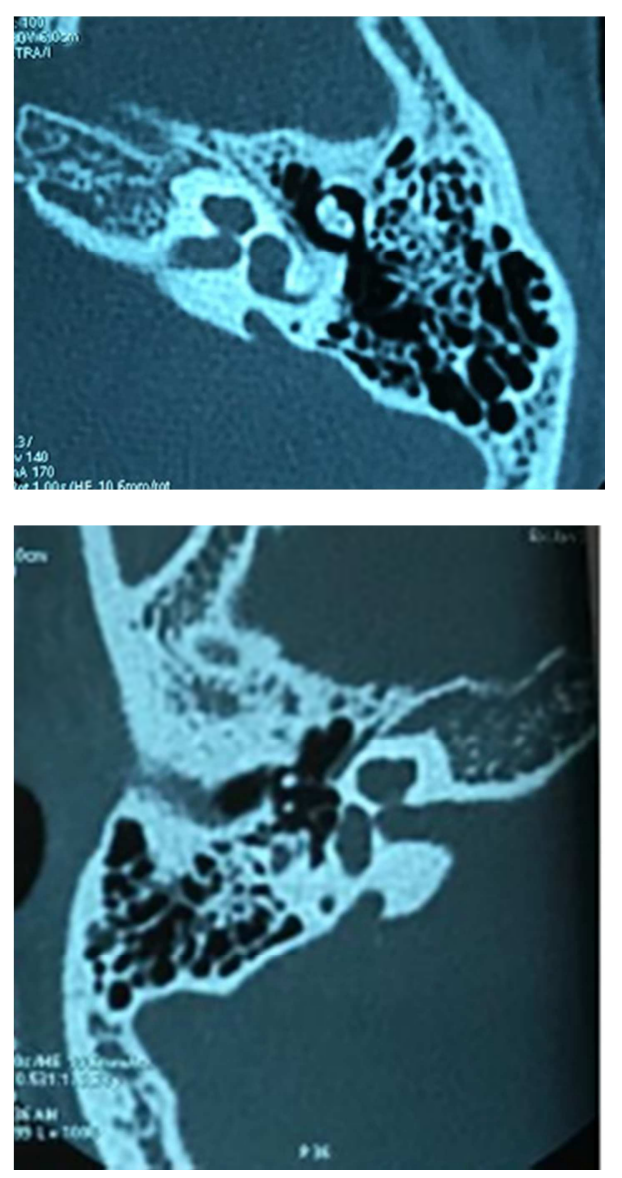

Figure 1. Axial computed tomography scan of temporal bones showing bilateral enlarged vestibular aqueducts and modiolus deficiency.

Clinical and paraclinical data suggest the possibility of pendred syndrome.

Concerning therapeutic management, Total thyroidectomy was performed for the goiter (figure 2). The histopathology revealed a dystrophic adenomatous thyroid hyperplasia without signs of malignancy and the patient is on substitution therapy.

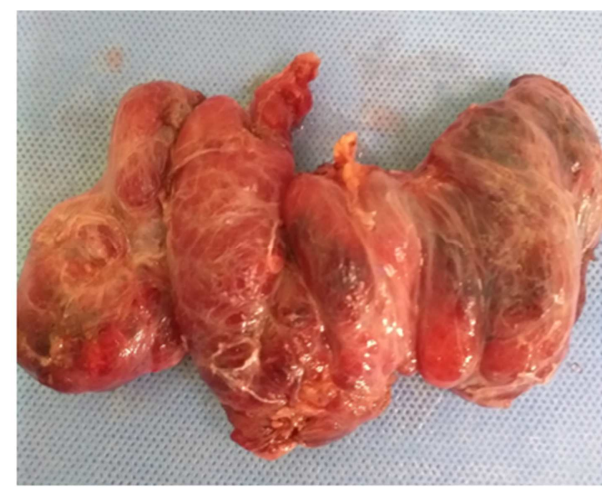

Figure 2. Isolated thyroid specimen following the thyroidectomy.

\section{Discussion}

Pendred syndrome is an autosomal recessive disorder, characterized by sensorineural hearing loss associated with dyshormonogenic goiter. This syndrome is the result of biallelic mutations in the Pendrin gene (PDS/SLC26A4) on chromosome $7 \mathrm{q} 31$, who codes for pendrin, a multifunctional protein whose expression has been documented in the inner ear, the thyroid and the kidney, also in a few other organs [2, 5].

In the thyroid, pendrin is expressed at the apical membrane of follicular cells. It ensures the transport of iodide to the follicular lumen, an essential step for the production of thyroid hormones. In Pendred syndrome, a defect in the Pendrin is responsible for impaired thyroid function hence the appearance of a dyshormonogenetic goiter [6].

in the inner ear; pendrin plays the role of chloride/ bicarbonate exchanger. It is expressed in the endolymphatque sac and duct its role is to ensure the homeostasis of the endolymph for a good functioning of the inner ear [7].

Pendrin in the kidney is resides in the apical membrane of intercalated cells in the cortical collecting duct she plays the role of a bicarbonate secretion mediator [8].

The classical clinical presentation consists of the sensorineural hearing loss, associated with variable goiter in terms of size and timing of diagnosis $[9,10]$. Usually sensorineural hearing loss is profound and congenital or prelingual, it is bilateral but asymmetrical. Rarely, hearing loss develops later with progressive aggravation, which may be caused by exposure to barotraumas or acoustic traumas [11]. In the pediatric population, clinical signs include a delay in language acquisition or lack of response to sounds.

The onset of goiter varies considerably in time and severity and can be affected by dietary iodide intake [12]. It is the result of a disorder of iodine incorporation with incomplete thyroxine synthesis [13], and the prevalence is inversely proportional to iodine intake [14]. Generally, goiter appears (63\%) in early adulthood [12]. But it can be present at birth [13]. The development of goiter is highly variable [9]. The thyroid may be normal in size in some patients [9], however in others it may be very large with retrosternal extension [16]. Thyroid function is variable, hypothyroidism has been described in 44 to $77 \%$ of goiters [12]. One of the most serious complications of goiter is the development of malignancies. The percentage of developing thyroid carcinoma in patients with pendred syndrome is $1 \%$ [17].

Confirmatory diagnosis is based on genetic studies which allow the detection of mutations in the Pendrin gene $[2,17]$. However, other examinations allow the orientation of the diagnosis such as CT scan and MRI of Inner Ear. Inner ear malformation is a frequent finding in Pendred syndrome. Vestibular enlargement and modiolus deficiency were the most found anomalies in this population, however, these malformations are not specific to Pendred Syndrome and may be found in other diseases [18].

The study of the organization of iodide can be made by the perchlorate discharge test which can objectify the organization of iodide defects by causing a discharge of inorganic iodide from the thyroid. A loss $\geq 10 \%$ indicates a defect in organization. Moreover, a negative test does not exclude the 
presence of Pendred syndrome as illustrated by several studies $[9,19]$.

In the majority of cases, the combination of clinical data and imaging results allows the start of therapeutic management. However, there is no specific treatment. Deficiencies in thyroid hormones can be supplemented, total thyroidectomy is proposed in the event of bulky goiter or suspicious thyroid nodule [20]. Hearing aids can be beneficial in the case of moderate hearing loss. Patients with severe or profound deafness should be tested for cochlear implantation [21]. Genetic testing should be offered to families and psychological support may also be required.

\section{Conclusion}

Pendred syndrome is a common cause of congenital deafness.

Clinical presentation is very variable. However, the association of goiter and progressive deafness suggests the diagnosis of Pendred syndrome.

Vestibular enlargement and modiolus deficiency were the most found anomalies in this population.

Therapeutic management is non-specific.

\section{References}

[1] Pendred V. Deaf-mutism and goitre. Lancet 1896; ii: 532.

[2] Rozenfeld J, Efrati E, Adler L, Tal O, Carrithers SL, Alper SL, Zelikovic I. Transcriptional regulation of the pendrin gene. Cell. Physiol. Biochem. 2011; 28 (3): 385-96.

[3] Smith N, U-King-Im JM, Karalliedde J. Delayed diagnosis of Pendred syndrome. BMJ Case Rep. 2016 Sep 12; 2016.

[4] Wémeau JL, Kopp P. Pendred syndrome. Best Pract. Res. Clin. Endocrinol. Metab. 2017 Mar; 31 (2): 213-224).

[5] Heffield VC, Kraiem Z, Beck JC, et al. Pendred syndrome maps to chromosome $7 \mathrm{q} 21-34$ and is caused by an intrinsic defect in thyroid iodine organification. Nat Genet 1996; 12: 424-6.

[6] Bizhanova A, Kopp P. Minireview: The sodium-iodide symporter NIS and pendrin in iodide homeostasis of the thyroid. Endocrinology 2009; 150 (3): 1084-90.

[7] Royaux IE, Belyantseva IA, Wu T, et al. Localization and functional studies of pendrin in the mouse inner ear provide insight about the etiology of deafness in Pendred syndrome. J Assoc Res Otolaryngol 2003; 4: 394-404.

[8] Royaux IE, Wall SM, Karniski LP, et al. Pendrin, encoded by the Pendred syndrome gene, resides in the apical region of renal intercalated cells and mediates bicarbonate secretion. Proc Natl Acad Sci U S A 2001; 98: 4221-6.

[9] Ladsous M, Vlaeminck-Guillem V, Dumur V, Vincent C, Dubrulle F, Dhaenens CM, et al. 437 Analysis of the thyroid phenotype in 42 patients with Pendred syndrome and nonsyndromic 438 enlargement of the vestibular aqueduct. Thyroid. 2014; 24: 639-48.

[10] Bizhanova A, Kopp P. Genetics and phenomics of Pendred syndrome. Mol Cell Endocrinol 2010; 322: 83-90.

[11] Cremers WR, Bolder C, Admiraal RJ, Everett LA, Joosten FB, van Hauwe $\mathrm{P}$, et al. Progressive sensorineural hearing loss and a widened vestibular aqueduct in Pendred syndrome. Arch Otolaryngol Head Neck Surg. 1998; 124: 501-5.

[12] Reardon W, Coffey R, Chowdhury T, Grossman A, Jan H, Britton K. Prevalence, age of onset and natural history of thyroid disease in Pendred syndrome. J Med Genet 1999; 36: 595-8].

[13] Boniver R. Le syndrome de Pendred. Cah ORL 1988; XXIII (7): 485-7].

[14] Arwert LI, Sepers JM. Goitre and hearing impairment in a patient with Pendred syndrome. Neth J Med 2008; 66: 118-20].

[15] Sreekar H, Uppia V, Patil S, Mutkekar A. Pendred SyndromE with Retrosternal Goitre. ndian J Surg 2013. 2013; 75: S329-S30.

[16] Guo-Xia Tong1 \& Qing Chang1 \& Diane Hamele-Bena \& John Carew1 \& Richard S. Hoffman1 \& Marina N. Nikiforova \& Yuri E. Nikiforov. Targeted Next-Generation Sequencing Analysis of a Pendred Syndrome-Associated Thyroid Carcinoma Endocr Pathol. 2016 Mar; 27 (1): 70-5.].

[17] Fugazzola L, Mannavola D, Cerutti N, Maghnie M, Pagella F, Bianchi P, et al. Molecular analysis of the Pendred's syndrome gene and magnetic resonance imaging studies of the inner ear are essential for the diagnosis of true Pendred's syndrome. J Clin Endocrinol Metab. 2000; 85: 2469-75.

[18] Goldfeld, M., Glaser, B., Nassir, E., Gomori, J. M., Hazani, E., \& Bishara, N. (2005). CT of the Ear in Pendred Syndrome. Radiology, 235 (2), 537-540.

[19] Preedy V, Burrow G, Watson R, editors. The Comprehensive Handbook on Iodide. San 465 Diego: Elsevier; 2009. p. 231-41.

[20] Tong, G.-X., Chang, Q., Hamele-Bena, D., Carew, J., Hoffman, R. S., Nikiforova, M. N., c \& Nikiforov, Y. E. (2016). Targeted Next-Generation Sequencing Analysis of a Pendred Syndrome-Associated Thyroid Carcinoma. Endocrine Pathology, 27 (1), 70-75.

[21] Van Nierop, J. W. I., Huinck, W. J., Pennings, R. J. E., Admiraal, R. J. C., Mylanus, E. A. M., \& Kunst, H. P. M. (2016). Patients with Pendred syndrome: is cochlear implantation beneficial? Clinical Otolaryngology, 41 (4), 386-394. 